\title{
Analysis of interleukin 19 serum levels and single nucleotide polymorphisms in systemic lupus erythematosus
}

\author{
J.R. Lin*, H.H. Qin*, Y. Wang, J. Liang and J.H. Xu \\ Department of Dermatology, Huashan Hospital Fudan University, Shanghai, \\ China \\ *These authors contributed equally to this study. \\ Corresponding author: J.H. Xu \\ E-mail: jinhuaxusci@163.com
}

Genet. Mol. Res. 15 (2): gmr. 15028007

Received November 5, 2015

Accepted February 12, 2016

Published April 27, 2016

DOI http://dx.doi.org/10.4238/gmr.15028007

\begin{abstract}
Systemic lupus erythematosus (SLE) is an autoimmune connective tissue disease that affects multiple organs and diminishes a patients' quality of life. It has been suggested that interleukin 19 (IL19) is engaged in intercellular signal transduction, which is related to the immune response and the local inflammatory reaction. Single nucleotide polymorphisms (SNPs) have been used to explore the genetic basis underlying the pathogenesis of SLE. In this study, we investigated the potential correlation between the functional IL19 SNP rs2243188 and SLE. The frequency of allele C in rs2243188 was lower in the SLE population, particularly when the dominant inheritance model was applied. There was also a significant difference in the allele $\mathrm{C}$ frequency between the lupus nephritis (LN) and non-LN groups in both the dominant and recessive inheritance models. In addition, we identified significant differences in the serum IL-19 levels between the different classes of SLE. Although this study is still at the preliminary stage, the correlations between the IL19 SNP and SLE, and between the
\end{abstract}


IL-19 levels and the different subclasses of SLE provide a reference for further exploration.

Key words: Single nucleotide polymorphism; Lupus nephritis; IL-19; Systemic lupus erythematosus; Hardy-Weinberg equilibrium

\section{INTRODUCTION}

Systemic lupus erythematosus (SLE) is an autoimmune connective tissue disease that affects multiple systems and multiple organs, and diminishes the quality of life of patients (Agmon-Levin et al., 2012). Currently, the disease is more prevalent in young women, and the occurrence of early-onset, mild, and atypical cases has been increasing (Danchenko et al., 2006). Some patients show "temporary" onset and recover after a few months of treatment; some severe cases (except patients with diffuse proliferative glomerulonephritis) can be alleviated without therapeutic interference. SLE is distributed widely and displays a distinct distribution pattern in relation to race, region, age, gender, and the individual (Vyse and Kotzin, 1998; Yang et al., 2010; Cui et al., 2013). The relevant data show that the incidence of SLE in China is about 5/10,000: higher than in Japan, or European and American countries (Godarzi et al., 2011; Cui et al., 2013). Concurrently, there is evidence that the pathogenesis of SLE is associated with familial genetics (Shai et al., 1999; Wakeland et al., 2001; Mangale et al., 2013), ultraviolet radiation (McGrath Jr., 1994; McGrath et al., 1996), estrogen levels in vivo (Lahita, 1999; Pierdominici and Ortona, 2013; Young et al., 2014), drugs (Fernandes Moça Trevisani et al., 2013; Gurevitz et al., 2013; Hahn, 2013), and food and infections (Sciascia et al., 2012; Touma et al., 2013), etc. However, the pathogenesis of SLE requires further investigation.

The proliferation, differentiation, and function of cells in the immune system are subject to regulation by a series of cytokines, which can be divided into the following categories based on structural homology: the protein family, the hematopoietic growth factor family, and the tumor necrosis factor family (Paik et al., 2007) (Paik et al., 2007). The protein family includes interleukin families 1, 6, and 16. Interleukin 19 (IL-19), a member of the interleukin 16 family, comprises 153 amino acids with an alpha helical structure. IL-19 not only regulates and promotes the proliferation of antigen-presenting cells, but also binds IL-20R- $\alpha$ and IL20R- $\beta$ to jointly complete intercellular signal transduction (Papatriantafyllou, 2013a,b). STAT1 and STAT-3 are activated by IL-19 (Wang et al., 2012; Fonseca-Camarillo et al., 2014). Moreover, IL-19 is involved in the immune response, is correlated to the local inflammation reaction and tissue injury, and it serves as a signal transduction factor. A single nucleotide polymorphism (SNP) is a DNA sequence polymorphism generated by a single nucleotide mutation at the genomic level. SNPs are one of the most common heritable mutations in the human genome, and account for more than $90 \%$ of all known polymorphisms (Han et al., 2009; Cui et al., 2013). With the rapid development of molecular biology, the examination of SNPs has become a common tool for exploring the genetic basis of common and complicated diseases, and for identifying susceptible genes. SNPs have been used to identify associations between interleukins and SLE (Ni et al., 2014; Qi et al., 2015). In this study, we investigated the correlation between the level of serum IL-19 and the IL-19 gene (IL19) SNP rs2243188 with the incidence and clinical characteristics of SLE. To do this we determined the genotypes and gene frequencies of rs2243188 in SLE patients and healthy people. 


\section{MATERIAL AND METHODS}

\section{Research subjects}

The experimental group comprised 548 SLE patients diagnosed in the Department of Rheumatology at our hospital between September 2012 and May 2014, comprising 51 males $(9.3 \% ; 17-41$ years old; average age $24.5+8.1$ years $)$, and 497 females $(90.7 \% ; 15-49$ years old; average age $23.9+7.8$ years). The classification of SLE was conducted according to the 1997 revision of the American College of Rheumatology (ACR) guidelines. The control group comprised 548 healthy people who had been physically examined in our hospital in May 2014: 53 males $(9.7 \%$; 17-42 years old; average age, $25.1+7.9$ years), and 495 females (90.3\%; 16-49 years old; average age $24.2+8.2$ years). The control subjects were selected according to the following criteria: they did not meet any of the items in the 1997 ACR-revised diagnostic classifications standard for SLE; neither they nor their immediate relatives had any autoimmune diseases; and they were not receiving any long-term medication.

Written informed consent was obtained from all participants, and the study met with the approval of the Research Ethics Committee of our hospital.

\section{IL19 SNP treatment}

In the present study, the $I L 90$ gene rs 2243188 locus was selected as a research target because this locus has low minor allele frequency and has a group of functional SNPs. We investigated the relationship between the rs2243188 SNP and SLE by processing the sera of the experimental and control groups as follows. We collected 2-mL venous blood samples from each subject, extracted the human peripheral blood DNA, and marked and genotyped the DNA using the following procedure: 1) we added and thoroughly mixed $5 \mathrm{~mL}$ cell lysis buffer (FG1), and centrifuged the mixture at $5000 \mathrm{rpm}$ for $10 \mathrm{~min}$; 2) after centrifugation, we removed the supernatant, added $0.5 \mathrm{~mL} \mathrm{FG2/Qiagen} \mathrm{protease} \mathrm{mixture,} \mathrm{and} \mathrm{stirred} \mathrm{until} \mathrm{the}$ blood cells were fully disrupted; 3 ) we centrifuged the lysate, added $1 \mathrm{~mL}$ isopropanol, and re-centrifuged at a low speed for $5 \mathrm{~min}$; 4) after centrifugation, we removed the supernatant, immersed the settled substances in $1.5 \mathrm{~mL} 75 \%$ alcohol, and re-centrifuged at a low speed for $10 \mathrm{~min} ; 5)$ we added DNA lysis buffer (FG3) to the precipitate, and mixed in a water-bath at $70^{\circ} \mathrm{C}$; and 6) we subjected the DNA lysate to agitation for $6 \mathrm{~h}$, and harvested the human peripheral blood DNA after electrophoresis.

\section{Determination of IL-19 serum levels}

A human serum IL-19 enzyme-linked immunosorbent assay (ELISA) kit (96-well and 48well) was used to measure the optical density (OD) at $450 \mathrm{~nm}$ of $1.5 \mathrm{~mL}$ serum from each subject. We used the following reagents: DNA lysis buffer (FG3), double-distilled water $\left(\mathrm{ddH}_{2} \mathrm{O}\right)$, cell lysis buffer (FG1), ultra-pure water, and a human serum IL-19 ELISA kit (96-well and 48-well).

We used the following instruments: an ultra-pure water generator (Chongqing Aikepu Co., Ltd., CN), a polymerase chain reaction (PCR) Master Mix (ABI, USA), a $-80^{\circ} \mathrm{C}$ Sanyo refrigerator (Sanyo Motor Co., Ltd., JP), a Meiling BCD-251 refrigerator (Hefei Meiling Co., Ltd.), a PCV-3000 low-temperature and high-speed centrifuge (Grant Bio, UK), and an ELX800 microplate reader (BioTek Instruments Equipment Co., Ltd., USA). 


\section{Statistical processing}

SPSS13.0 statistical software was used for statistical analyses. Data are reported as means $\pm \mathrm{SE}$. Counting data are expressed as compositional ratio and rate. The $t$-test was used for inter-groups contrasts, and the chi-square test was used for inter-group comparisons. The rank sum test was used for grading data. Differences were considered statistically significantly when $\mathrm{P} \leq 0.05$.

\section{RESULTS}

\section{Common data contrast results}

All participants were of Chinese Han descent. There were no significant differences between the experimental and control groups in age and gender stratification $(\mathrm{P}>0.05$, Table 1).

Table 1. Comparison of age and sex ratio in the experimental and control groups.

\begin{tabular}{l|c|c}
\hline Group & Age & Sex ratio (male/female) \\
\hline Experimental & $24.1 \pm 8.4$ & $51 / 497$ \\
\hline Control & $24.5 \pm 7.9$ & $53 / 495$ \\
\hline
\end{tabular}

\section{Correlation between the IL19 SNP and SLE}

\section{Comparison between the rs2243188 locus polymorphism in IL19 and SLE genetic susceptibility}

Genotyping of the rs2243188 locus in the IL19 gene was carried out by PCR. The rs2243188 locus in both groups met the Hardy-Weinberg equilibrium test (Figure 1).

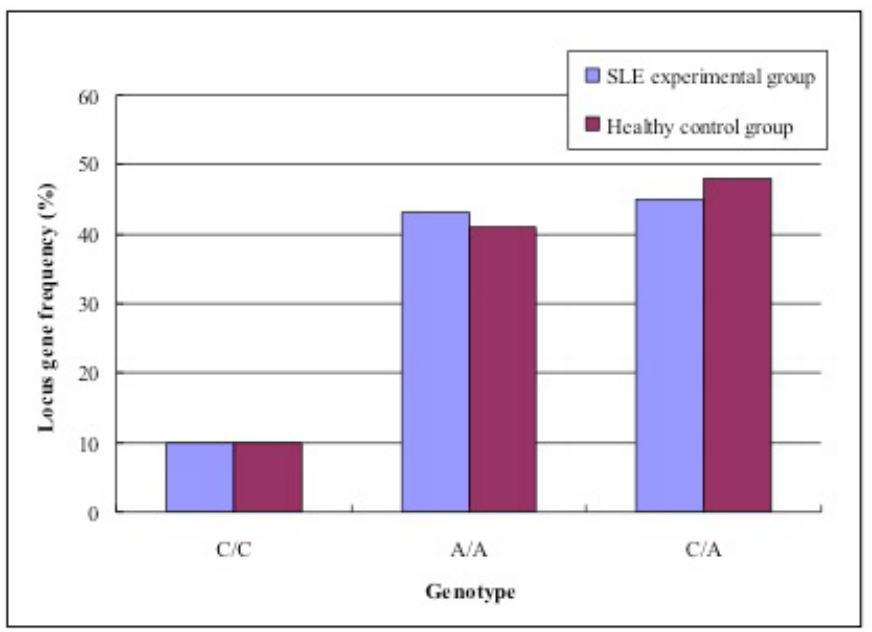

Figure 1. shows that there was no significant difference between the experimental and control groups in the distribution of genotype frequency. We calculated the allele frequency and genotype distribution in the dominant/ negative model in genotyped rs2243188 loci A and C (Table 2). 
Table 2 shows that there was a significant difference in the frequency of the $\mathrm{C}$ allele of rs2243188 $(\mathrm{P}<0.05)$. The gene frequency distribution was significantly different in the dominant inheritance model $(\mathrm{P}<0.05)$, while the difference was not significant for the recessive inheritance model $(\mathrm{P}>0.05)$.

Table 2. Gene frequency distribution of the rs 2243188 locus of the IL19 gene in the experimental and the control groups.

\begin{tabular}{l|c|c|c|c|c|c}
\hline \multirow{2}{*}{ rs2243188 } & \multicolumn{2}{|c|}{ Allele } & \multicolumn{2}{c|}{ Dominant model } & \multicolumn{2}{c}{ Negative model } \\
\cline { 2 - 7 } & A & C & AA & CC + CA & CC & AA + CA \\
\hline Experimental group [N (\%)] & $375(68.4 \%)$ & $173(31.6 \%)$ & $255(46.5 \%)$ & $293(53.5 \%)$ & $53(9.7 \%)$ & $495(90.3 \%)$ \\
\hline Control group [N (\%)] & $364(66.4 \%)$ & $185(33.6 \%)$ & $234(42.7 \%)$ & $314(57.3 \%)$ & $56(10.2 \%)$ & $492(89.8 \%)$ \\
\hline
\end{tabular}

\section{Comparison of the rs2243188 locus in IL19 in lupus nephritis (LN)}

LN is an important clinical symptom of SLE. The clinical symptoms of renal involvement include proteinuria, the presence of red and white blood cells in the urine, a decline in glomerular filtration function, and renal tubular dysfunction. $\mathrm{LN}$ has a serious impact on SLE recovery and is one of the causes of death from SLE. Therefore, we investigated the relationship between the rs2243188 locus of the IL19 gene and LN. In the experimental group, 261 patients had LN symptoms, i.e., $47.6 \%$ of the total number in the experimental group. See Table 3 for gene frequency distribution.

Table 3. Gene frequency distribution of the rs 2243188 locus of the $I L 19$ gene in the lupus nephritis (LN) and non-LN patient groups.

\begin{tabular}{l|c|c|c|c|c|c}
\hline \multirow{2}{*}{ rs2243188 } & \multicolumn{2}{|c|}{ Allele } & \multicolumn{2}{c|}{ Dominant model } & \multicolumn{2}{c}{ Negative model } \\
\cline { 2 - 7 } & A & C & AA & CC+CA & CC & AA + CA \\
\hline LN (N (\%)) & $195(35.6 \%)$ & $80(14.6 \%)$ & $130(23.7 \%)$ & $157(28.6 \%)$ & $31(5.7 \%)$ & $210(38.3 \%)$ \\
\hline Non-LN (N (\%)) & $180(32.8 \%)$ & $93(17.0 \%)$ & $125(22.8 \%)$ & $136(24.8 \%)$ & $22(4.0 \%)$ & $285(52.0 \%)$ \\
\hline
\end{tabular}

Table 3 shows that the frequency distribution of minor allele $\mathrm{C}$ was significantly different $(\mathrm{P}<0.05)$. Significant difference was also found between the $\mathrm{LN}$ and non-LN groups in both the dominant and recessive inheritance models $(\mathrm{P}<0.05)$.

\section{Correlation between the level of serum IL-19 and SLE}

To make the data comparable, we divided the SLE patients into nine groups: malar rash, arthritis, oral ulcer, discoid lupus, light sensitivity, hypo-complement, fever, hematuria, and proteinuria groups. The malar rash group contained 60 patients and the other groups had 61 patients each. The serum IL-19 levels in the nine groups were determined and the results are listed in Table 4.

The rank sum test on two samples as per the results in Table 4 showed that the differences in serum IL-19 levels in the oral ulcer, light sensitivity, and hematuria groups were significant $(\mathrm{P}<0.05)$, but there were no significant differences in the other groups. Table 4 also indicates that the serum IL-19 levels in the positive patients in the oral ulcer, hematuria, and proteinuria groups were $78.3,32.1$, and $20.6 \%$ higher than those in the negative patients, respectively; the serum IL-19 levels in the positive patients in the light sensitivity and discoid lupus groups declined significantly. 
Table 4. IL-19 serum levels in the systemic lupus erythematosus (SLE) patients.

\begin{tabular}{|c|c|c|c|c|c|c|c|}
\hline Clinical symptom group & $\begin{array}{c}\text { Test } \\
\text { result }\end{array}$ & $\begin{array}{c}\text { Cases } \\
{[\mathrm{N}(\%)]}\end{array}$ & $\begin{array}{c}\text { Serum IL-19 } \\
\text { level (pg/mL) }\end{array}$ & Clinical symptom group & $\begin{array}{c}\text { Test } \\
\text { result }\end{array}$ & $\begin{array}{c}\text { Cases } \\
{[\mathrm{N}(\%)]}\end{array}$ & $\begin{array}{r}\text { Serum IL-19 } \\
\text { level }(\mathrm{pg} / \mathrm{mL})\end{array}$ \\
\hline \multirow[t]{2}{*}{ Malar rash } & 1 & $30(5.5 \%)$ & 33.01 & \multirow[t]{2}{*}{ Hypo-complement } & 1 & $25(4.6 \%)$ & 36.97 \\
\hline & 0 & $30(5.5 \%)$ & 32.05 & & 0 & $36(6.6 \%)$ & 33.24 \\
\hline \multirow[t]{2}{*}{ Arthritis } & 1 & $37(6.8 \%)$ & 31.94 & \multirow[t]{2}{*}{ Fever } & 1 & $17(3.1 \%)$ & 30.25 \\
\hline & 0 & $24(4.4 \%)$ & 33.96 & & 0 & $44(8.0 \%)$ & 32.94 \\
\hline \multirow[t]{2}{*}{ Oral ulcer } & 1 & $3(0.5 \%)$ & 56.87 & \multirow[t]{2}{*}{ Hematuria } & 1 & $19(3.5 \%)$ & 42.06 \\
\hline & 0 & $58(10.6 \%)$ & 31.9 & & 0 & $42(7.7 \%)$ & 31.85 \\
\hline \multirow[t]{2}{*}{ Discoid lupus } & 1 & $13(2.4 \%)$ & 25.99 & \multirow[t]{2}{*}{ Proteinuria } & 1 & $23(4.2 \%)$ & 38.56 \\
\hline & 0 & $48(8.8 \%)$ & 33.56 & & 0 & $38(6.9 \%)$ & 31.97 \\
\hline \multirow[t]{2}{*}{ Light sensitivity } & 1 & $2(0.4 \%)$ & 19.8 & & & & \\
\hline & 0 & $59(10.8 \%)$ & 33.26 & & & & \\
\hline
\end{tabular}

"1" indicates that the patients suffered from the symptom and "0" indicates they did not.

\section{CONCLUSIONS}

To date, no concordant conclusion has been drawn on the pathogenesis of SLE. Previous research has suggested that genetic factors are significantly associated with the disease. Therefore, it is very important to screen and investigate the genes that are related to SLE susceptibility. Additionally, some researchers think that the serum IL-19 level can affect normal kidney activity and cause SLE (Barrett et al., 2009; Leffler et al., 2014) (Leffler, Bengtsson, and Blom 2014; Barrett et al., 2009). To explore the correlation between the serum IL-19 level, SNPs, and SLE, the rs2243188 locus was investigated in the present paper. The allele frequency of rs 2243188 was subjected to the Hardy-Weinberg equilibrium test, and a correlation between the rs2243188 SNP and LN was found. In addition, ELISA revealed that the serum IL-19 level and rs2243188 SNP locus in the IL19 gene in 548 SLE patients of Chinese Han descent were highly correlated to genetic susceptibility to the disease ${ }^{10}$. The allele C frequency in rs 2243188 in the Chinese Han population was correlated with a lower incidence of SLE. The expression levels of serum IL-19 in the positive patients were significantly higher in the oral ulcer, hematuria, and proteinuria groups, but significantly lower in the positive patients in the light sensitivity and discoid lupus groups.

However, this paper has the following shortfalls. First, the scope of the research was confined and a larger sample size, taking into account different races, regions, and populations, is required (Yang et al., 2010) (Yang et al., 2010). Second, the results were from a crosssectional survey; the serum IL-19 expression level before treatment was not determined, and the serum IL-19 level was not followed-up after treatment. Third, the screening conditions were less stringent in the control group, with a lower exclusion level ${ }^{12,13}$. The present study revealed the genetic variation and expression level of IL-19 in relation to SLE, indicating that further studies on the specific pathogenesis of the disease are warranted.

\section{Conflicts of interest}

The authors declare no conflict of interest.

\section{ACKNOWLEDGMENTS}

Research supported by the Basic Research Creative Program of Science Technology of Shanghai (Grant \#12JC1401900), the Excellent Academic Leaders Program of Shanghai 
(Grant \#13XD1401300), and the National Natural Science Foundation of China (Grant \#81373212 and Grant \#81402605).

\section{REFERENCES}

Agmon-Levin N, Mosca M, Petri M and Shoenfeld Y (2012). Systemic lupus erythematosus one disease or many? Autoimmun. Rev. 11: 593-595. http://dx.doi.org/10.1016/j.autrev.2011.10.020

Barrett JC, Clayton DG, Concannon P, Akolkar B, et al.; Type 1 Diabetes Genetics Consortium (2009). Genome-wide association study and meta-analysis find that over 40 loci affect risk of type 1 diabetes. Nat. Genet. 41: 703-707. http://dx.doi.org/10.1038/ng.381

Cui Y, Sheng Y and Zhang X (2013). Genetic susceptibility to SLE: recent progress from GWAS. J. Autoimmun. 41: 2533. http://dx.doi.org/10.1016/j.jaut.2013.01.008

Danchenko N, Satia JA and Anthony MS (2006). Epidemiology of systemic lupus erythematosus: a comparison of worldwide disease burden. Lupus 15: 308-318. http://dx.doi.org/10.1191/0961203306lu2305xx

Fernandes Moça Trevisani V, Castro AA, Ferreira Neves Neto J and Atallah AN (2013). Cyclophosphamide versus methylprednisolone for treating neuropsychiatric involvement in systemic lupus erythematosus. Cochrane Database Syst. Rev. 2: CD002265.

Fonseca-Camarillo G, Furuzawa-Carballeda J, Granados J and Yamamoto-Furusho JK (2014). Expression of interleukin (IL)-19 and IL-24 in inflammatory bowel disease patients: a cross-sectional study. Clin. Exp. Immunol. 177: 64-75. http://dx.doi.org/10.1111/cei.12285

Godarzi EM, Sarvestani EK, Aflaki E and Amirghofran Z (2011). Interleukin-6 gene polymorphism in Iranian patients with systemic lupus erythematosus. Clin. Rheumatol. 30: 179-184. http://dx.doi.org/10.1007/s10067-010-1452-0

Gurevitz SL, Snyder JA, Wessel EK, Frey J, et al. (2013). Systemic lupus erythematosus: a review of the disease and treatment options. Consult Pharm. 28: 110-121. http://dx.doi.org/10.4140/TCP.n.2013.110

Hahn BH (2013). Belimumab for systemic lupus erythematosus. N. Engl. J. Med. 368: 1528-1535. http://dx.doi. org/10.1056/NEJMct1207259

Han JW, Zheng HF, Cui Y, Sun LD, et al. (2009). Genome-wide association study in a Chinese Han population identifies nine new susceptibility loci for systemic lupus erythematosus. Nat. Genet. 41: 1234-1237. http://dx.doi.org/10.1038/ng.472

Lahita RG (1999). The role of sex hormones in systemic lupus erythematosus. Curr. Opin. Rheumatol. 11: 352-356. http:// dx.doi.org/10.1097/00002281-199909000-00005

Leffler J, Bengtsson AA and Blom AM (2014). The complement system in systemic lupus erythematosus: an update. Ann. Rheum. Dis. 73: 1601-1606. http://dx.doi.org/10.1136/annrheumdis-2014-205287

Mangale D, Kariuki SN, Chrabot BS, Kumabe M, et al. (2013). Familial aggregation of high tumor necrosis factor alpha levels in systemic lupus erythematosus. Clin. Dev. Immunol. 2013: 267430. http://dx.doi.org/10.1155/2013/267430

McGrath Jr H (1994). Ultraviolet-A1 irradiation decreases clinical disease activity and autoantibodies in patients with systemic lupus erythematosus. Clin. Exp. Rheumatol. 12: 129-135.

McGrath H, Martínez-Osuna P and Lee FA (1996). Ultraviolet-A1 (340-400 nm) irradiation therapy in systemic lupus erythematosus. Lupus 5: 269-274. http://dx.doi.org/10.1177/096120339600500405

Ni J, Zhang M, Zhu Y, Chen GM, et al. (2014). Association study of interleukin-19 rs2243188 polymorphism with systemic lupus erythematosus in a Chinese population. Autoimmunity 47: 378-382. http://dx.doi.org/10.3109/08916 934.2014.914505

Paik JK, Kim OY, Koh SJ, Jang Y, et al. (2007). Additive effect of interleukin-6 and C-reactive protein (CRP) single nucleotide polymorphism on serum CRP concentration and other cardiovascular risk factors. Clin. Chim. Acta 380: 68-74. http://dx.doi.org/10.1016/j.cca.2006.11.011

Papatriantafyllou M (2013a). Cytokines: true to their family name. Nat. Rev. Immunol. 13: 544-545. http://dx.doi. org $/ 10.1038 /$ nri3496

Papatriantafyllou M (2013b). Host response: true to their family name. Nat. Rev. Microbiol. 11: 508-511.http://dx.doi. org/10.1038/nrmicro3083

Pierdominici M and Ortona E (2013). Estrogen impact on autoimmunity onset and progression: the paradigm of systemic lupus erythematosus. Int. Trends Immun. 1: 22-34.

Qi JH, Qi J, Xiang LN and Nie G (2015). Association between IL-21 polymorphism and systemic lupus erythematosus: a meta-analysis. Genet. Mol. Res. 14: 9595-9603. http://dx.doi.org/10.4238/2015.August.14.22

Sciascia S, Ceberio L, Garcia-Fernandez C, Roccatello D, et al. (2012). Systemic lupus erythematosus and infections: clinical importance of conventional and upcoming biomarkers. Autoimmun. Rev. 12: 157-163. http://dx.doi. org/10.1016/j.autrev.2012.03.009 
Shai R, Quismorio FP, Jr., Li L, Kwon OJ, et al. (1999). Genome-wide screen for systemic lupus erythematosus susceptibility genes in multiplex families. Hum. Mol. Genet. 8: 639-644. http://dx.doi.org/10.1093/hmg/8.4.639

Touma Z, Haddad A, Gladman DD, Uleryk EM, et al. (2013). Skin nontuberculous mycobacterial infection in systemic lupus erythematosus: an unusual skin infection mimicking lupus vasculitis. Semin. Arthritis Rheum. 42: 498-506. http://dx.doi.org/10.1016/j.semarthrit.2012.08.002

Vyse TJ and Kotzin BL (1998). Genetic susceptibility to systemic lupus erythematosus. Annu. Rev. Immunol. 16: $261-292$. http://dx.doi.org/10.1146/annurev.immunol.16.1.261

Wakeland EK, Liu K, Graham RR and Behrens TW (2001). Delineating the genetic basis of systemic lupus erythematosus. Immunity 15: 397-408. http://dx.doi.org/10.1016/S1074-7613(01)00201-1

Wang F, Smith N, Maier L, Xia W, et al. (2012). Etanercept suppresses regenerative hyperplasia in psoriasis by acutely downregulating epidermal expression of interleukin (IL)-19, IL-20 and IL-24. Br. J. Dermatol. 167: 92-102. http:// dx.doi.org/10.1111/j.1365-2133.2012.10961.x

Yang W, Shen N, Ye DQ, Liu Q, et al.; Asian Lupus Genetics Consortium (2010). Genome-wide association study in Asian populations identifies variants in ETS1 and WDFY4 associated with systemic lupus erythematosus. PLoS Genet. 6: e1000841. http://dx.doi.org/10.1371/journal.pgen.1000841

Young NA, Wu LC, Burd CJ, Friedman AK, et al. (2014). Estrogen modulation of endosome-associated toll-like receptor 8: an IFN $\alpha$-independent mechanism of sex-bias in systemic lupus erythematosus. Clin. Immunol. 151: 66-77. http:// dx.doi.org/10.1016/j.clim.2014.01.006 